\title{
Wybrane własności aluminiowych złączy spawanych wiązką elektronów
}

\author{
Selected properties of aluminum joints \\ welded by electron beam
}

\section{Streszczenie}

Przedmiotem badań były złącza spawane wiązką elektronów w aluminiowych kołach tłumika drgań. Przeprowadzono badania makro- i mikroskopowe, pomiary twardości oraz próby statyczne rozciągania złączy.

Słowa kluczowe: spawanie wysokoenergetyczne; wiązka elektronów; stopy aluminium

\section{Abstract}

The subject of research was welded joints with the electron beam of aluminum wheels of the vibration damper. Were performed macroscopic and microscopic examination, hardness measurements and static tensile testing.

Keywords: high energy welding; electron beam; aluminium alloys

\section{Wstęp}

Wiązka elektronów jako źródło ciepła do spawania jest znana i stosowana w przemyśle od wielu lat. Po raz pierwszy użyto ją w latach 50-tych ubiegłego wieku. Pomimo długoletniej historii jest nadal powszechnie popularna w przemyśle. Bogate doświadczenie Instytutu Spawalnictwa w tym zakresie zaowocowało opracowaniem szeregu nowych technologii wytwarzania części maszyn oraz narzędzi skrawających, w których konieczne było połączenie części z różnych materiałów albo o różnej geometrii [1].

Spawanie wiązką elektronów oferuje zupełnie nowe możliwości projektowania złączy spawanych w zakresie kombinacji materiałów łączonych oraz ich kształtów geometrycznych, trudnych lub niemożliwych do osiągnięcia w technologii konwencjonalnej $[2,3]$.

Technologia ta umożliwia uzyskanie wysokiej jakości połączeń ze wszystkich spawalnych metali konstrukcyjnych w bardzo szerokim zakresie grubości od 0,025 $\div 300 \mathrm{~mm}$ [4]. Wśród licznych zalet jakości złączy spawanych wiązką elektronów wymienia się głównie pomijalnie małą strefę SWC, wysoką jednorodność struktury i korzystny rozkład twardości [5]. Tym nie mniej nie zaleca się stosowania wiązki elektronów do spawania stali węglowych oraz zawierających dużo siarki i fosforu, a także metali niskotopliwych w tym brązów i mosiądzów [6].

Ważną pozycję zajmuje wiązka elektronów w produkcji lotniczych silników turbinowych, gdzie spawa się tą metodą tarcze sprężarki, czopy, wały, dźwignie, koła zębate i kadłuby [6].

Spawanie wiązką elektronów jest procesem wydajnym i precyzyjnym stąd jego szerokie zastosowanie w przemyśle elektronicznym, elektrotechnicznym, w budowie części maszyn oraz w motoryzacji $[4,7]$. Niniejszy artykuł nawiązuje do zastosowania wiązki elektronów w motoryzacji i przedstawia wyniki badań jakości złączy spawanych na przykładzie koła tłumika drgań.

\section{Przedmiot badań - charakterystyka}

Własności złączy spawanych wiązką elektronów rozważano na przykładzie aluminiowego koła tłumika drgań wykonanego ze stopu AlMg3, przedstawionego na rysunku 1 wraz z zaznaczonymi miejscami poboru próbek do badań metalograficznych. Koło składa się korpusu i tarczy połączonych dwoma spoinami obwodowymi. Próbki Z1 i Z2 oznaczają spoinę zewnętrzną, a W1 i W2 spoinę wewnętrzną. Próbki Z2 i W2 zostały pobrane z miejsc zakończenia spoin.

\section{Analiza chemiczna}

Analizy składu chemicznego materiałów tarczy i korpusu wykonano metodą spektralną z użyciem analizatora emisyjnego $w$ wyładowaniem jarzeniowym firmy LECO, stosując następujące parametry: $\mathrm{U}=800 \mathrm{~V}, \mathrm{I}=45 \mathrm{~mA}$, argon. Wyniki analizy zawarte $w$ tabeli 1, stanowią średnią arytmetyczną z pięciu pomiarów. Analiza wykazała, że obie części koła wykonane są ze stopu aluminium gat. AW 5754 (AlMg3).

Dr inż. Artur Lange, dr inż. Piotr Białucki, prof. dr hab. inż. Andrzej Ambroziak, dr inż. Wiesław Derlukiewicz, mgr inż. Ewa Harapińska - Politechnika Wrocławska, mgr inż. Andrzej Kosman - Rywal-RHC.

Autor korespondencyjny/Corresponding author. artur.lange@pwr.edu.pl 
Tablica I. Analiza chemiczna materiałów podstawowych koła

Table I. Chemical composition of base materials of the wheel

\begin{tabular}{|c|c|c|c|c|c|c|c|c|c|c|c|c|}
\hline Składnik [\%] & Si & Mg & $\mathrm{Fe}$ & $\mathrm{Cu}$ & Sn & Zn & $\mathrm{Cr}$ & $\mathrm{Ni}$ & Mn & $\mathrm{Pb}$ & Al & $\mathrm{Ti}$ \\
\hline Tarcza & 0,178 & 3,160 & 0,341 & 0,035 & 0,004 & 0,039 & 0,046 & 0,021 & 0,233 & 0,021 & 95,900 & 0,025 \\
\hline Korpus & 0,163 & 3,300 & 0,315 & 0,042 & 0,001 & 0,039 & 0,053 & 0,021 & 0,313 & 0,023 & 95,700 & 0,038 \\
\hline EN 573-3:2013 & $<0,40$ & $2,6-3,6$ & $<0,40$ & $<0,10$ & $<0,05$ & $<0,20$ & $<0,30$ & $<0,05$ & $<0,50$ & $<0,05$ & reszta & $<0,15$ \\
\hline
\end{tabular}

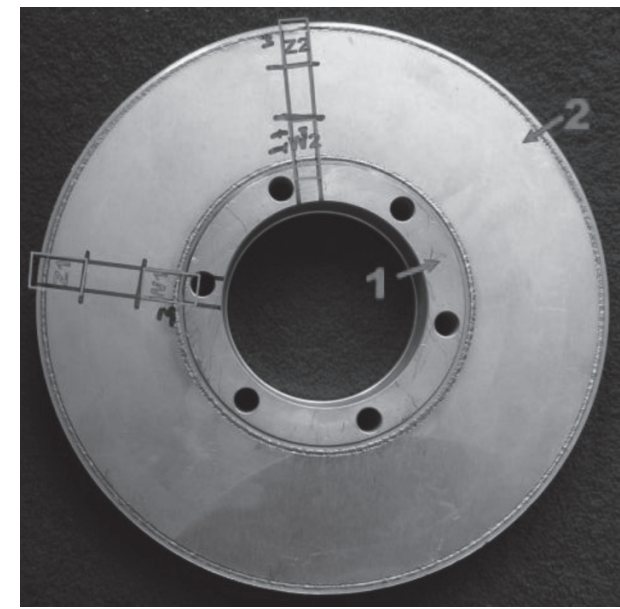

Rys. 1. Koło aluminiowe; 1 - korpus, 2 - tarcza

Fig. 1. Aluminium wheel; 1 - body, 2 - disk

\section{Badania metalograficzne}

\section{Badania makroskopowe}

Badania wykonano na mikroskopie stereoskopowym OLYMPUS ZX7. Na rysunkach 2 i 3 przedstawiono budowę złączy spawanych, na których widać front krystalizacji spoiny. Rowek spawalniczy przygotowany był na I bez odstępu z zamkiem o głębokości $5 \mathrm{~mm}$ i szerokości $1 \mathrm{~mm}$ ustalającym położenie tarczy względem korpusu. Badania ujawniły prawidłowy kształt spoiny, charakterystyczny dla metod o wysokiej koncentracji energii, czyli dużą głębokość wtopienia i mały kąt rozwarcia. Średnia głębokość wtopienia wynosiła $7 \mathrm{~mm}$ dla obu spoin, zewnętrznej i wewnętrznej, a szerokość lica zmieniała się w granicach od 2,5 do 2,9 mm.

Widoczny na rysunkach 2 i 3 charakterystyczny układ „tusek" spoiny wskazuje na poprawny dobór parametrów spawania w końcowej części spoiny w celu zapewnienia prawidłowego wypełnienia krateru.

\section{Badania mikroskopowe}

Badania wykonano na mikroskopie optycznym OLYMPUS CK40M przy powiększeniu od 50 do 500x. Zgłady metalograficzne trawiono odczynnikiem Kellera (do stopów aluminium). Mikrostruktury badanych spoin przedstawiono na rysunku 4.

Spoiny w części łączącej tarczę z korpusem koła nie wykazały niezgodności spawalniczych. Jedynie w dolnej części spoiny, występującej w korpusie poza materiałem tarczy, stwierdzono lokalnie występujące pęcherze (rys. 4b), które często spotykane są w spoinach z niepełnym przetopieniem, charakterystycznych dla metod o wysokiej koncentracji energii jak spawanie laserowe i elektronowe. Lokalizacja pęcherzy i niewielka ich ilość nie miały istotnego wpływu na własności mechaniczne złączy.

Na rysunku 5 przedstawiono mikrostrukturę złącza spawanego występującą na granicy wtopienia spoiny w materiał rodzimy korpusu koła. Budowa spoiny jest charakterystyczna dla stopu AIMg3, która składa się z roztworu stałego oraz wydzieleń faz międzymetalicznych na granicach komórek.
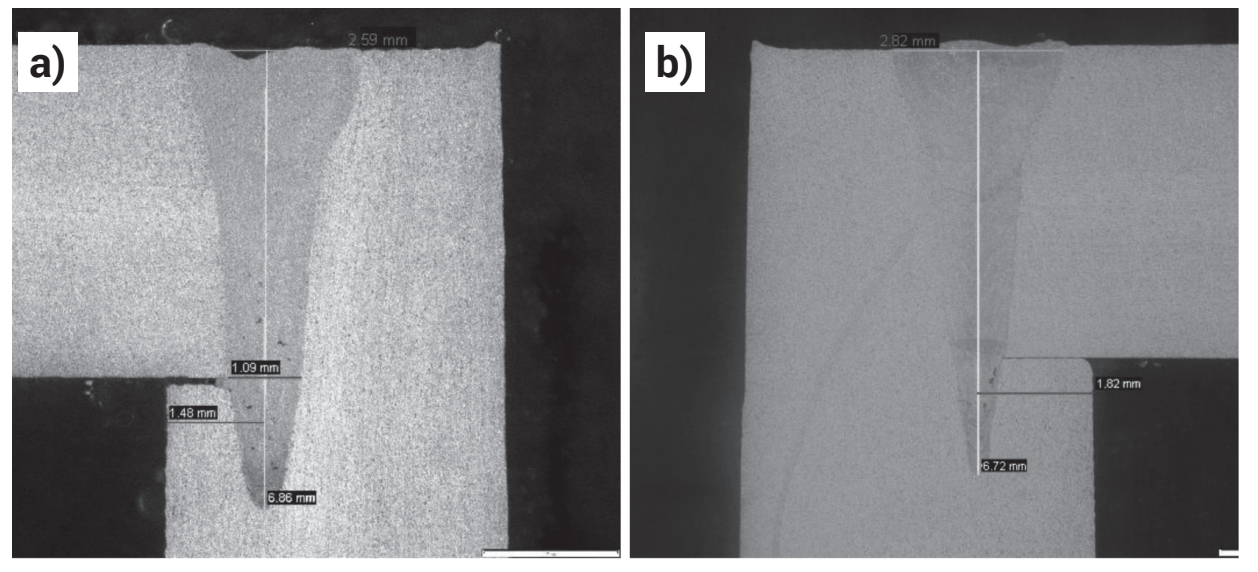

Rys. 2. Makrostruktura spoiny: a) zewnętrznej Z1; b) wewnętrznej W1. Pow. $x 15$

Fig. 2. Macrostructure of the welds: a) from outside $Z 1$; b) from inside $W 1$. Magn. x15
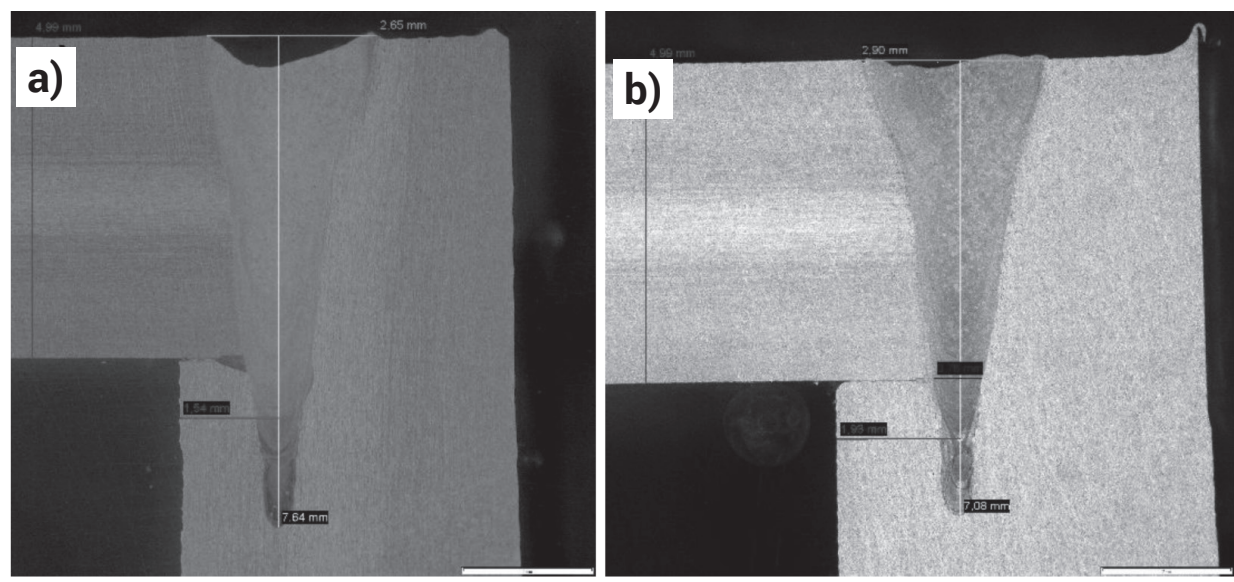

Rys. 3. Makrostruktura a) spoiny zewnętrznej Z2; b) spoiny wewnętrznej W2. Pow. x15

Fig. 3. Macrostructure of the welds: a) from outside $Z 2$; b) from inside $W 2$. Magn. x15 

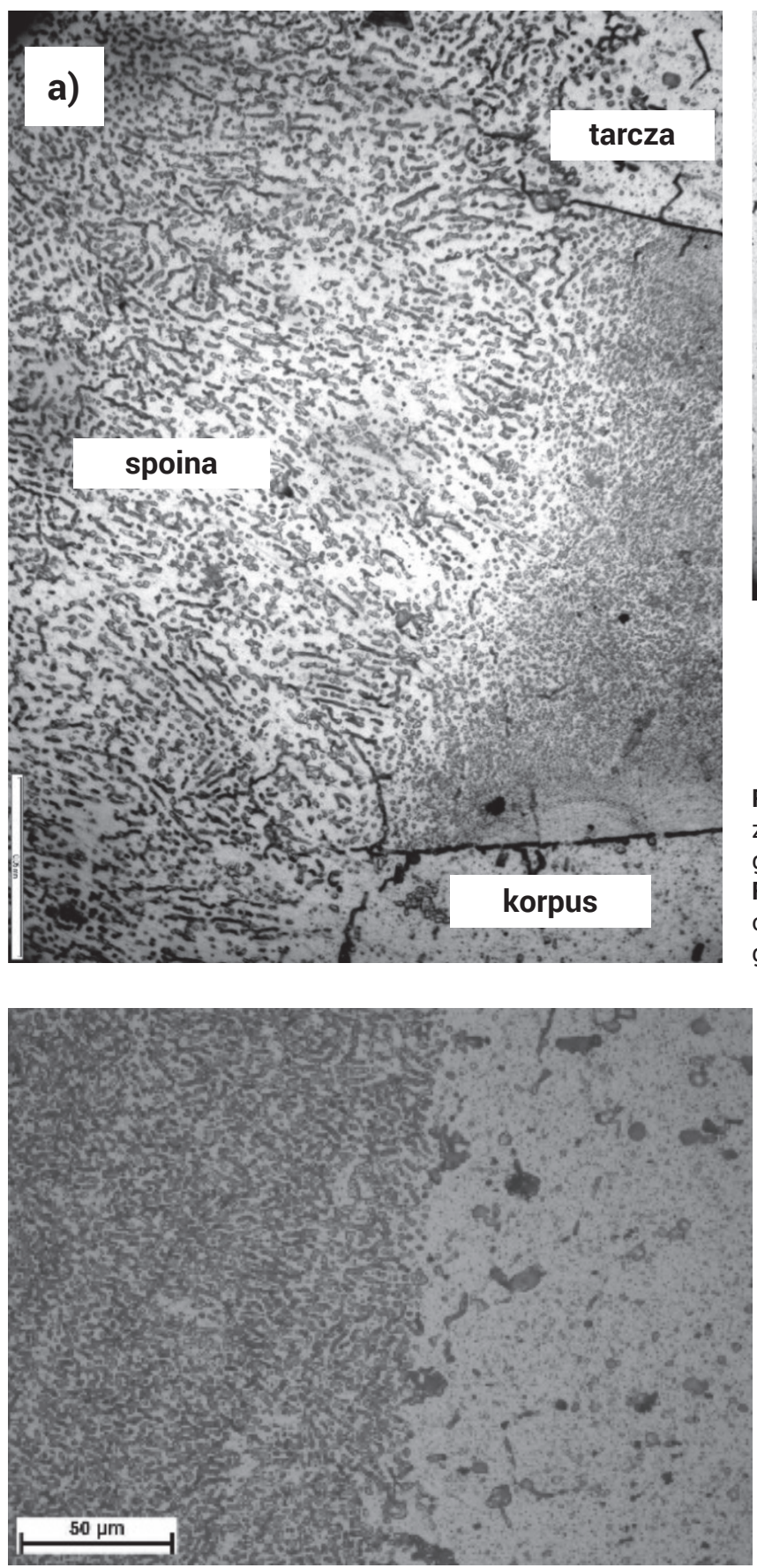

Rys. 5. Mikrostruktura na granicy wtopienia w materiał rodzimy korpusu koła. Traw. Mi1. Pow. 500x

Fig. 5. Microstucture of weld on the border of fusion in the base material of the wheel body. Magn. x500. Reagent M1

\section{Pomiary makro- i mikrotwardości}

Twardość Brinella materiału rodzimego części składowych koła, zmierzona twardościomierzem WPM, wynosiła ok. 72 HBW 62,5/2,5.

Pomiary mikrotwardości wykonano na twardościomierzu Sinowon HVS-1000 przy obciążeniu 9,8N. Zakres pomiarów obejmował materiał rodzimy, strefy wpływu SWC i spoinę. W obszarze wymieszania (wtopienia) wykonano dodatkowe pomiary wzdłuż spoiny. Układ punktów pomiarowych oraz wyniki pomiarów mikrotwardości dla spoin zewnętrznej i wewnętrznej pokazano odpowiednio na rysunkach 6 i 7 .

Wyniki pomiarów twardości wskazują na niewielki wzrost twardości w obszarze spoiny w porównaniu do materiałów rodzimych korpusu oraz tarczy koła.

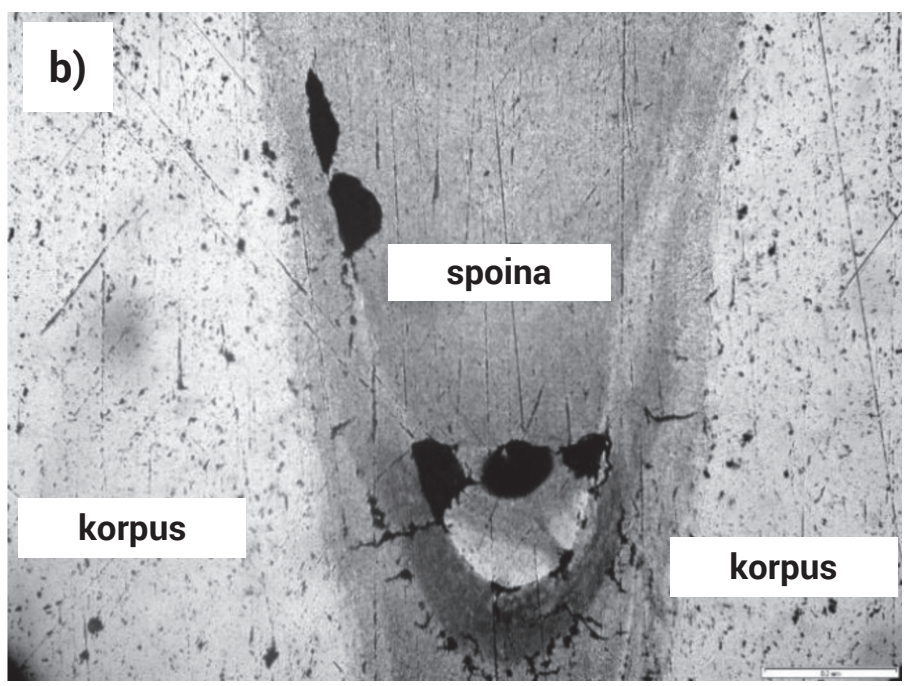

Rys. 4. Mikrostruktury: a) spoiny zewnętrznej $Z 1$ w okolicy styku tarczy z korpusem (zamek). Pow. x500; b) spoiny wewnętrznej W1 w obszarze grani w miejscu zakończenia ściegi. Pow. x100;

Fig. 4. Microstructures: a) of outside weld $Z 1$ in the area of contact of disk and body (support). Magn. x500; b) of inside weld W1 in the region of end of the stitch. Magn. x100
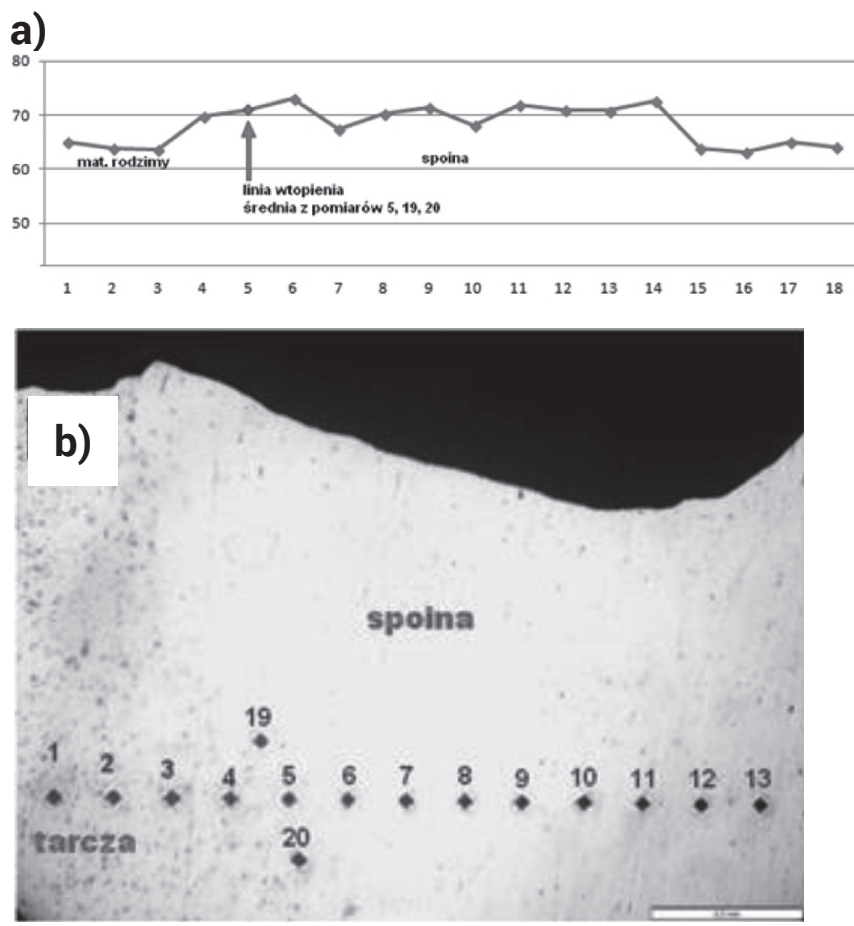

Rys. 6. Rozkład twardości HV01 w złączu aluminium ze spoiną zewnętrzną. 1-4 = MR+SWC, 5- linia wtopienia, 6-14 spoina, 15-18 = SWC+MR

Fig. 6. Distribution of hardness HV01 in the joint shield to the body of the wheel with external weld. 1-4 = BM+HAZ, 5 fusion line, 6-14 weld, 15-18 = HAZ + BM 
a)

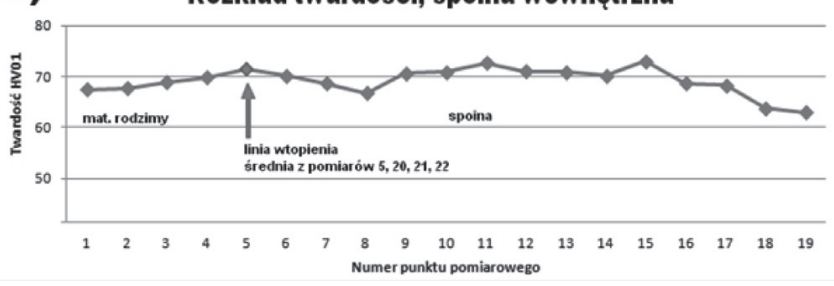

Rys. 7. Rozkład twardości HV01 w złączu aluminium ze spoiną wewnętrzną. 1-4 = MR+SWC, 5- linia wtopienia, 6-15 spoina, 16-19SWC+MR

Fig. 7. Distribution of hardness HV01 in the joint shield to the body of the wheel with internal weld. 1-4 $=\mathrm{BM}+\mathrm{HAZ}, 5$ fusion line, 6-15 weld, 16-19 = HAZ + BM

\section{Badania wytrzymałościowe}

Spoiny podczas pracy koła poddane są przede wszystkim naprężeniom ścinającym. Z uwagi na niestandardową geometrię zrywanych próbek, wykonano specjalne oprzyrządowanie mocujące rozciągane próbki złączy w szczękach zrywarki (rys. 8) celem określenia wytrzymałości na ścinanie $\mathrm{R}_{\mathrm{t}}$.

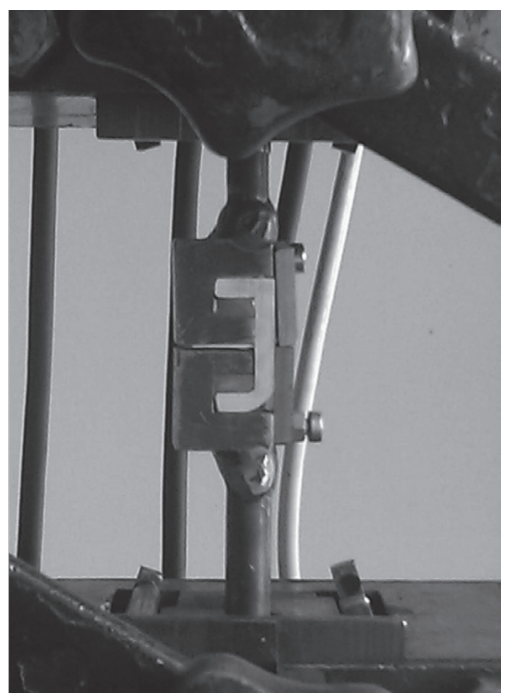

Rys. 8. Widok przyrządu do badania wytrzymałości złączy ze spoiną obwodową zewnętrzną

Fig. 8. Wiew of a device for testing the strength of joints with the outer peripheral weld

Tablica II. Wyniki badań wytrzymałości próbek na rozciąganie

Table II. Results of static tensile testing

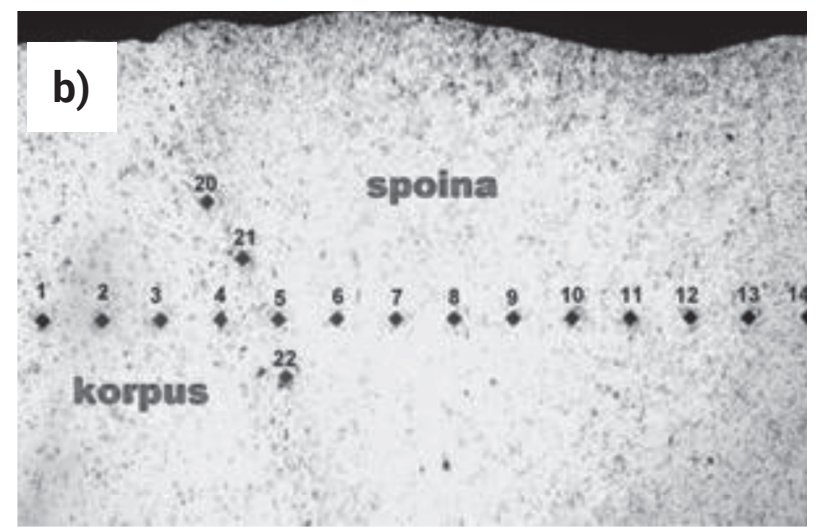

Próbę wytrzymałości złączy przeprowadzono na maszynie wytrzymałościowej firmy Louis Schopper na zakresie pomiarowym $0 \div 20 \mathrm{kN}$, przy prędkości posuwu belki $V_{b}=5 \mathrm{~mm} / \mathrm{min}$. Wyniki próby rozciągania zamieszczono w tablicy II.

Podczas rozciągania złączy ze spoiną zewnętrzną zerwanie próbki następowało w materiale rodzimym korpusu koła tuż pod granią spoiny we wszystkich czterech próbkach. Dlatego określono wytrzymałość na rozciąganie $R_{m}$, a nie wytrzymałość na ścinanie $R_{t}$. Wygląd próbek po rozciąganiu pokazano na rysunku $9 a$.

Tylko w jednym przypadku złączy ze spoiną wewnętrzną koła, w pierwszej próbce (próbka nr 1, rys. 9b), nastąpiło ścięcie w spoinie, natomiast w pozostałych trzech próbkach zerwanie nastąpiło $\mathrm{w}$ materiale rodzimym korpusu koła, podobnie jak w przypadku spoiny zewnętrznej, co pokazano na rysunku $9 b$.

Jak wynika z tablicy II wytrzymałość złączy spawanych jest blisko o połowę mniejsza niż materiału podstawowego. Może to wynikać z oddziaływania cieplnego spawania oraz z niestandardowej geometrii rozciąganych próbek.

\begin{tabular}{|c|c|c|c|c|c|c|}
\hline Nr próbki & Rodzaj złącza & $\mathrm{F}_{\mathrm{t}}[\mathrm{N}]$ & $\mathrm{F}_{\mathrm{m}}[\mathrm{N}]$ & $\mathrm{S}_{\mathrm{o}}\left[\mathrm{mm}^{2}\right]$ & $\mathbf{R}_{\mathrm{t}}[\mathrm{MPa}]$ & $\mathbf{R}_{\mathrm{m}}[\mathrm{MPa}]$ \\
\hline Pokrywa & Mat. rodzimy & - & 19410 & 98 & - & 198 \\
\hline Korpus & Mat. rodzimy & - & 24610 & 96 & - & 256 \\
\hline 1 & \multirow{4}{*}{ Zewnętrzne } & - & 9450 & 80,8 & - & 117 \\
\hline 2 & & - & 8550 & 79,9 & - & 107 \\
\hline 3 & & - & 8310 & 79,9 & - & 104 \\
\hline 4 & & - & 9490 & 79 & - & 120 \\
\hline 1 & \multirow{4}{*}{ Wewnętrzne } & 8330 & - & 100 & 83 & - \\
\hline 2 & & - & 7580 & 79,8 & - & 95 \\
\hline 3 & & - & 8750 & 80,3 & - & 109 \\
\hline 4 & & - & 7830 & 74 & - & 105 \\
\hline
\end{tabular}



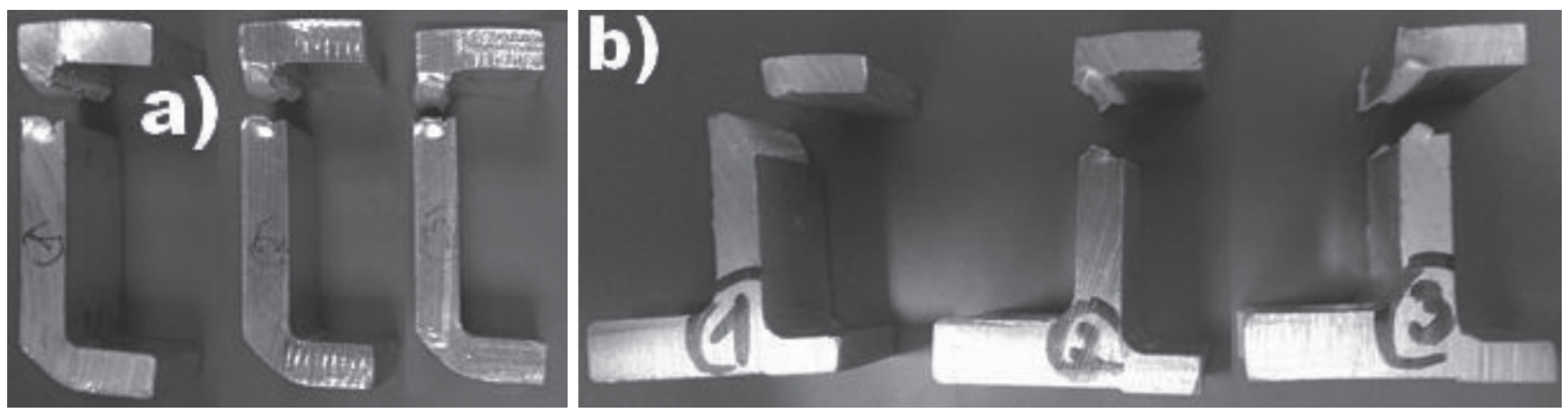

Rys. 9. Wygląd próbek po rozciąganiu złączy: a) ze spoiną zewnętrzną, b) ze spoiną wewnętrzną

Fig. 9. Appearance of samples after stretching of joints: a) with the outer weld, b) with the inner weld

\section{Wnioski}

Przeprowadzone badania wykazały, że spawanie wiązką elektronów tarczy z korpusem koła tłumika drgań skrętnych jest bardzo efektywną metodą łączenia. Wąska spoina i duża szybkość spawania nie powodują odkształceń koła i widocznego rozrostu ziaren w strefie SWC. Występujące w grani spoiny nieliczne pęcherze są charakterystyczne dla spoin bez pełnego przetopu. Z uwagi na ich małą ilość i umiejscowienie w dolnej części spoiny w materiale korpusu poniżej grubości materiału tarczy, nie miały wpływu na obniżenie własności mechanicznych złączy.

Pomiary twardości wykazały niewielki, ok. 8 HV0,1, wzrost twardości w spoinie w porównaniu do materiału rodzimego tarczy oraz korpusu koła. Jest to prawdopodobnie spowodowane wydzieleniem faz międzymetalicznych w roztworze stałym magnezu w aluminium.

Podczas statycznej próby rozciągania złączy próbki ulegały zerwaniu w korpusie koła w dolnej płaszczyźnie zamka, w miejscu o najmniejszym przekroju nośnym, którego grubość wynosiła ok. 4 mm (przy grubości ścianek równych 5 mm). Tylko w jednym przypadku próbka uległa ścinaniu po linii wtopienia od strony korpusu.

\section{Literatura}

[1] Jerzy Dworak: Biuletyn Instytutu Spawalnictwa, 2015 r., nr 1, s. 53-62.

[2] Aleksander Zawada: Spawarka elektronowa, Elektronika Praktyczna 11/2015, s. 53-57.

[3] Anna Grochowska: Proces spawania elektronowego, STAL Metale \& Nowe

[4] Pilarczyk J., Węglowski M. St.: Spawanie wiązką elektronów, Przegląd Spawalnictwa, 2015 r, Vol. 87, nr 10 s. 124-129.
[5] Nowacki J., Pietrzak K.: Mikrostruktura i właściwości warstw nadtapianych wiązką elektronową, Przegląd Spawalnictwa 11/2012, s. 22-28.

[6] Godzimirski J.: Nowe technologie lotniczych silników turbinowych, Prace Instytutu Lotnictwa, Warszawa 2011, 213, s. 22-36.

[7] Zatyka H.: Spawanie wiązką elektronów, WNT, Warszawa 1968, Technologie, wrzesień-październik 2009r. 